\title{
When the purpose lies within: Maximizers and satisfaction with autotelic choices
}

\author{
Michail D. Kokkoris ${ }^{1}$
}

Published online: 15 November 2017

(C) The Author(s) 2017. This article is an open access publication

\begin{abstract}
Are maximizers less satisfied with their choices than satisficers? This research provides a novel perspective on this question by distinguishing between two types of consumer goals: autotelic, when choice is a goal in itself, and instrumental, when a choice is a means to achieving other goals. Study 1 showed that maximizers value autotelic experiences more than satisficers. Study 2 experimentally manipulated the choice goal and found that maximizers compared to satisficers experience higher choice satisfaction when the choice goal is autotelic rather than instrumental. Additionally, evidence is provided for the underlying mechanism (perceived ease of choice) as well as downstream consequences (consumers' willingness to pay for their chosen option). These findings advance a conceptualization of maximizers as consumers seeking self-contained meaning in choice and provide new insights into the relation between maximizing and choice satisfaction. Theoretical and practical implications for consumer decision-making are discussed.
\end{abstract}

Keywords Maximizing $\cdot$ Choice satisfaction $\cdot$ Goals $\cdot$ Autotelic $\cdot$ Meaning $\cdot$ Consumer decision-making

\section{Introduction}

Are consumers who aim to make the best possible choice (maximizers) less satisfied with their choices than consumers who tend to settle for a "good enough" option (satisficers)? This seems to be what many studies that examine this question suggest (Besharat et al. 2014; Carrillat et al. 2011; Chowdhury et al. 2009; Iyengar et al. 2006; Leach and Patall 2013; Polman 2010; Schwartz et al.

Michail D. Kokkoris

michail.kokkoris@wu.ac.at

1 Department of Marketing, Institute for Marketing and Consumer Research, WU Vienna University of Economics and Business, Welthandelsplatz 1, 1020 Vienna, Austria 
2002). However, other studies have recently cast doubt on these conclusions and argued that maximizing might not be detrimental for choice satisfaction and subjective well-being (Dalal et al. 2015; Kokkoris 2016; Lai 2010; Oishi et al. 2014; Rim et al. 2011; Weinhardt et al. 2012; Zhu et al. 2017). The current article contributes to this debate by advancing a more nuanced approach to maximizing and its relation with choice satisfaction. Specifically, it focuses on consumer choice goals as a previously unacknowledged factor that can influence maximizers' satisfaction with their choices. The main proposition of this article is that maximizers (compared to satisficers) are consumers that seek self-contained meaning in choice. As such, they are more satisfied with autotelic choices, which are inherently rewarding, rather than with instrumental choices, which are used as means to achieve external goals.

This research contributes to the literature on maximizing and consumer decisionmaking by proposing a novel moderator of maximizers' satisfaction with their choices. At the same time, it adds to the growing literature mentioned above that questions the assumption that maximizers are less happy than satisficers. Going beyond this literature, the current research examines maximizers' context-dependent satisfaction (as a response to choice) rather than broader assessments of life satisfaction. From a managerial perspective, this research provides useful insights how to increase maximizers' satisfaction with their choices. An autotelic frame of choice-focusing on the choice itself rather than any external benefits - is a tool that marketers could use to satisfy consumers who are maximizers.

\subsection{Autotelic versus instrumental goals}

The word autotelic, from the Greek auto (self) and telos (goal), means having a meaning and purpose in and not apart from itself (Csikszentmihalyi 1997). In decision-making, an autotelic choice can be defined as a choice that derives its meaning and purpose from within, from the act of choosing itself. This is the case when consumption experiences are "sought as goals in themselves and not as intermediate steps to achieve higher-end goals" (Botti and McGill 2011, p. 1067). In contrast, an instrumental choice can be defined as a choice that does not contain its meaning and purpose but rather derives it from outside the act of choosing. This is the case when consumption experiences "serve a goal beyond that inherent in the experience itself" (Botti and McGill 2011, p. 1067). To illustrate, an autotelic choice would be to choose a specific dish on the menu for the sheer pleasure of eating, whereas an instrumental choice would be to choose a certain dish in order to learn about a foreign culture (Botti and McGill 2011). This distinction draws on self-determination theory, which investigates the effects of intrinsic and extrinsic goals on motivation (Ryan and Deci 2000).

In the marketing literature, several studies have examined the differentiated impact of autotelic and instrumental goals. For example, Choi and Fishbach (2011) found that when the act of choosing serves as its own end, consumers experience less depletion than when the act of choosing is a means to an external goal. Similarly, Laran and Janiszewski (2011) found that volitional behaviors that are construed as work (extrinsically motivated) deplete self-control resources, whereas volitional behaviors that are construed as fun (intrinsically motivated) replete them. Botti and McGill (2011) 
showed that being able to choose (versus having the choice externally imposed) increases satisfaction when choice is autotelic but not when it is instrumental. Taken together, these studies suggest that autotelic goals can be more motivating and rewarding than instrumental ones. The current research integrates autotelic choice goals into the maximizing literature as a novel factor that boosts maximizers' satisfaction with their choices and argues that autotelic choice goals are more motivating for maximizers than for satisficers.

\subsection{Maximizers and preference for autotelic experiences}

Prior research has suggested that engagement in autotelic goals can be conceptualized as a personality trait (Asakawa 2004; Baumann 2012; Busch et al. 2013; Csikszentmihalyi 1990; Johnson et al. 2014; Ross and Keiser 2014). Individuals with an autotelic personality engage in activities for their own sake, because they are inherently rewarding, and not in order to achieve a specific goal. This quality has been described by Csikszentmihalyi (1997) as disinterested interest because it denotes "a focus on task-inherent as opposed to purpose-related incentives" (Baumann 2012, p.167). Domain-specific individual differences in autotelic versus instrumental goals have also been examined in the marketing literature, for example, with regards to consumers' need for touch (Peck and Childers 2003). The current research argues that individual differences in engagement in autotelic goals can also be of relevance to research on maximizing. Given the association between autotelic personality and openness to challenges and persistence (Baumann 2012), it could be argued that maximizers, who strive for the best, value autotelic experiences more than satisficers, who settle for merely "good enough." Moreover, given that autotelic individuals are motivated more by intrinsic rather than extrinsic rewards (Nakamura and Csikszentmihalyi 2002), maximizers might also value intrinsic goals more than extrinsic goals.

Hypothesis 1a: Maximizers value autotelic experiences more than satisficers.

Hypothesis 1b: Maximizers value intrinsic (versus extrinsic) goals more than satisficers.

\subsection{Maximizers and choice satisfaction with autotelic goals}

Besides valuing autotelic experiences and intrinsic (versus extrinsic) goals more than satisficers, maximizers should also be more satisfied with autotelic (versus instrumental) choice goals compared to satisficers. This proposition builds on recent research showing that maximizers experience higher eudaimonic well-being than satisficers, although they do not differ in hedonic well-being (Kokkoris 2016). Eudaimonic wellbeing is related to meaningfulness, which is conceptually and empirically distinct from happiness (Baumeister et al. 2013). Contrary to popular belief that maximizers are unhappy individuals (e.g., Schwartz et al. 2002), they might be more inclined to seek meaning and purpose in life rather than positive affective experiences. Having high standards in choice might be one way for maximizers to achieve a meaningful life. This assumption is supported by empirical findings showing that maximizers underestimate 
time when choosing ("time flies"), which probably implies that they immerse themselves in the choice regardless of task requirements (Misuraca and Teuscher 2013). Thus, maximizers might experience a choice as more rewarding if it is framed as inherently meaningful and purposeful rather than as linked to an external purpose or a higher-end goal.

Hypothesis 2: An autotelic (versus instrumental) choice goal will result in higher choice satisfaction for maximizers than for satisficers.

\subsection{The mediating role of perceived ease}

Autotelic goals can be motivating (Choi and Fishbach 2011) and vitalizing (Laran and Janiszewski 2011), and autotelic engagement is associated with lower perceptions of stress and strain in demanding situations (Baumann 2012). Thus, an autotelic choice frame may make the search for the best look less strenuous and effortful. However, the subjective perception of ease of choice should be understood as contingent on regulatory fit-i.e., the "it-feels-right" experience that arises when people adopt goal strategies that match their goal orientations (Aaker and Lee 2006; Higgins 2005). A choice strategy that focuses consumers on seeking the best for the sake of choosing and not for any purpose outside choice should induce a stronger fit for maximizers, whose chronic goal orientation is to make the best choice, than for satisficers, who do not strive to invest heavily in choosing optimally. This sense of fit between choice goal and personal disposition should make choice feel easy and subsequently enhance satisfaction with the chosen option.

Hypothesis 3: The interaction effect of autotelic (versus instrumental) choice goal and maximizing on choice satisfaction will be mediated by perceived ease of choice.

\subsection{Downstream consequences on willingness to pay}

A related question is whether maximizers' higher satisfaction with autotelic versus instrumental choice also has downstream consequences on the monetary value consumers place on their chosen option. Does their higher satisfaction also translate into a higher willingness to pay (WTP) for the option of their choice? Consumer satisfaction is a driver of consumers' WTP for products and services (Homburg et al. 2005). Therefore, it was assumed that choice satisfaction might, in turn, increase maximizers' WTP in order to obtain the product of their choice. Specifically, by increasing maximizers' choice satisfaction, autotelic (versus instrumental) choice might also increase their WTP for their chosen option.

Hypothesis 4: An autotelic (versus instrumental) choice will increase maximizers' as opposed to satisficers' WTP for their chosen option through increasing choice satisfaction. 


\section{Study 1}

Study 1 is a correlational study that examines whether maximizers are drawn to autotelic goals more than satisficers (hypothesis 1).

\subsection{Method}

\subsubsection{Participants}

Data from 250 British participants were collected online on Prolific Academic (Peer et al. 2017). Data from 11 participants who failed to provide any answer to an openended question (see Sect. 2.1.2) were excluded from further analyses. The final sample comprised 239 participants (53 men, 186 women; age 18 to 84 years, $M=35.05$, $S D=10.53)$.

\subsubsection{Procedure}

Participants first completed the maximizing tendency scale (Diab et al. 2008) by indicating their agreement $(1=$ strongly disagree; $7=$ strongly agree $)$ with nine items ( $\alpha=0.85$; e.g., "No matter what it takes, I always try to choose the best thing"). This scale has been recommended as the most suitable measurement of the maximizing construct among the various available alternatives (Cheek and Schwartz 2016). Then, participants answered one question assessing the importance of autotelic goals adjusted from Csikszentmihalyi et al. (1993). The question was as follows: "How important is it for you to do something where you feel that the activity is worth doing in itself, even if there are no other benefits associated with it (for instance, financial reward, improved skills, recognition from others, and so on)?". Participants were also asked to provide their own examples of autotelic experiences in an open-ended question. Finally, participants filled out a short version of the aspirations index (Kasser and Ryan 1996) assessing the importance of various life goals ( $1=$ extremely unimportant; 7 = extremely important). Six items $(\alpha=0.79)$ pertained to the importance of three extrinsic life goals (fame, image, wealth; e.g., "To be admired by many people"), and eight items $(\alpha=0.81)$ pertained to the importance of four intrinsic life goals (community, relationships, health, growth; e.g., "To know and accept who I really am").

\subsection{Results}

Consistent with hypothesis $1 \mathrm{a}$, results showed that maximizing was positively associated with the importance of autotelic goals $(B=0.22 ; S E=0.10 ; p=.024)$. Moreover, consistent with hypothesis $1 \mathrm{~b}$, although participants who scored higher on maximizing assigned higher importance both to intrinsic life goals $(B=0.31, S E=0.05, p<.001)$ and extrinsic life goals $(B=.22, S E=.08, p=.006)$, maximizing was more strongly associated with intrinsic than extrinsic goals (Fisher's $z=1.98, p=.024$ (one-tailed)). Additionally, a significant interaction between intrinsic and extrinsic goals on maximizing $(B=-0.30, S E=0.11, p=.006,95 \% \mathrm{CI}=[-0.512,-0.087])$ suggests that maximizing was more pronounced among those assigning lower value to extrinsic but higher value to intrinsic goals $(B=0.75, S E=0.17, p<.001,95 \% \mathrm{CI}=[0.410,1.080])$. 
Descriptive statistics and inter-correlations of all measures are provided in Table 1. In short, study 1 shows that maximizers value autotelic experiences more than satisficers and are more likely than satisficers to pursue intrinsic compared to extrinsic life goals.

\section{Study 2}

Study 2 is an experimental study that examines whether maximizers are more satisfied with autotelic (versus instrumental) choices than satisficers (hypothesis 2). Moreover, the underlying mechanism based on perceived ease (hypothesis 3) as well as downstream consequences on WTP for the chosen option (hypothesis 4) were also investigated.

\subsection{Method}

\subsubsection{Participants}

Data from 208 US participants were collected online on Amazon MTurk (Buhrmester et al. 2011; Casler et al. 2013; Hauser and Schwarz 2016; Paolacci et al. 2010). Data from 21 participants who failed an attention check (see Sect. 3.1.2) were excluded from further analyses. The final sample comprised 187 participants (81 men, 106 women; age 18 to 72 years, $M=35.00, S D=11.24$ ).

\subsubsection{Procedure}

Participants first completed the maximizing tendency scale as in study 1 ( $\alpha=0.88$; Diab et al. 2008). Then, participants were informed that they would receive a menu consisting of ten types of cheese from which they had to pick one that was to their liking. At that point, participants were randomly assigned either to an autotelic goal condition, which focused participants on the inherent benefits of choosing (e.g., "this will enable you to find a cheese you will really like" and

Table 1 Descriptive statistics and inter-correlations of variables in study 1

\begin{tabular}{lllll}
\hline & 1 & 2 & 3 & 4 \\
\hline 1. Maximizing & - & - & - & - \\
2. Autotelic activities & $0.15^{*}$ & - & - & - \\
3. Intrinsic life goals & $0.36^{* *}$ & $0.12^{\dagger}$ & - & - \\
4. Extrinsic life goals & $0.18^{* *}$ & 0.05 & $0.24^{* *}$ & - \\
Mean & 4.80 & 5.35 & 5.92 & 3.50 \\
Standard deviation & 0.91 & 1.36 & 0.78 & 1.11 \\
Min. & 1.11 & 1.00 & 1.00 & 1.00 \\
Max. & 7.00 & 7.00 & 7.00 & 7.00 \\
Cronbach's alpha & 0.85 & - & 0.79 & 0.81 \\
\hline
\end{tabular}

$* p<.05 ; * * p<.01 ; \dagger p=.059$ 
"it is important that you can select an option you really want when deciding about something"), or an instrumental goal condition, which focused participants on an external purpose, namely, learning about cheese (e.g., "this will enable you to learn a lot about different cheeses" and "it is important that you have knowledge about what options are actually out there when deciding about something") (instructions adopted from McNeill et al. 2012, p. 327). Therefore, participants in both conditions had exactly the same task, that is, to choose a cheese of their liking, and only the choice goal, autotelic versus instrumental, varied. On the next page, participants were presented with ten cheese options. For each option, the name of the type of cheese and a picture were provided followed by brief information about the flavor, texture, source of milk, fat rate, origin, and usage. After choosing one type of cheese, participants were asked to rate their satisfaction with their choice ( $1=$ very unsatisfied; $7=$ very satisfied $)$ and the ease of making the choice ( 1 = very difficult; $7=$ very easy). Next, to assess participants' WTP for the chosen cheese, a choice titrator was used (McNeill et al. 2012). Participants were presented with consecutive offers to buy a piece of their chosen cheese, valued at $\$ 12$. These offers ranged from $\$ 0.50$ (lowest price) to $\$ 12.00$ (full price), with the price rising by $\$ 0.50$ per question. Participants were asked to indicate whether they would accept each offer. As a manipulation check, participants indicated to what extent each one of four items (interesting, enjoyable, meaningful, worthwhile; $\alpha=0.91$ ) described the choice task. The items were inspired by the intrinsic motivation inventory (Ryan 1982), which is a multidimensional instrument to assess participants' subjective experience of experimental tasks. All four items loaded on one factor that explained $78.54 \%$ of the total variance. Finally, participants indicated to what extent they considered themselves to be cheese experts $(1=$ not at all; $7=$ very much $)$ and completed an attention check (Oppenheimer et al. 2009).

\subsection{Results}

\subsubsection{Manipulation check}

Participants in the autotelic condition $(M=4.80, S D=1.50)$ experienced the choice task as more intrinsically motivating (i.e., interesting, enjoyable, meaningful, and worthwhile) than participants in the instrumental condition $(M=4.37, S D=1.54)$, $t(185)=1.91, p=.027$ (one-tailed), $d=0.28$. The manipulation was successful.

\subsubsection{Choice satisfaction}

To examine whether maximizers (compared to satisficers) are more satisfied with their choice when the goal is autotelic rather than instrumental (hypothesis 2), a moderation model with 5000 bootstraps was tested (PROCESS model 1; Hayes 2013). Choice goal (dummy-coded as $0=$ autotelic, $1=$ instrumental) served as the independent variable, maximizing as the moderator, and choice satisfaction as the dependent variable. Results showed a significant interaction between choice goal and maximizing ( $B=-0.34$, $S E=0.14, p=.014,95 \% \mathrm{CI}=[-0.601,-0.070]$ ) (Fig. 1). Spotlight analyses further indicated that maximizers (participants scoring $1 \mathrm{SD}$ above the mean, i.e., 5.73) were 


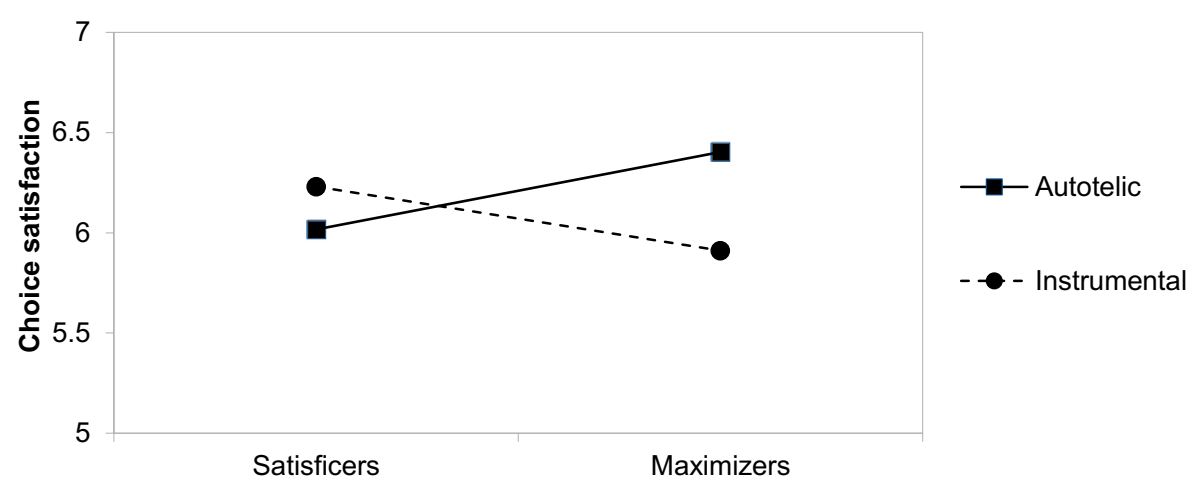

Fig. 1 Choice satisfaction as a function of choice goal (autotelic versus instrumental) and maximizing. Maximizers 1 SD above the scale mean; satisficers 1 SD below the scale mean (Maximizing Tendency Scale)

more satisfied with their choice in the autotelic $(M=6.40)$ than in the instrumental condition $(M=5.91)(B=-0.49, S E=0.20, p=.015,95 \% \mathrm{CI}=[-0.890,-0.098])$, whereas for satisficers (participants scoring $1 \mathrm{SD}$ below the mean, i.e., 3.63), there were no differences between autotelic $(M=6.02)$ and instrumental choices $(M=6.23)$ $(B=0.21, S E=0.20, p=.29,95 \% \mathrm{CI}=[-0.182,0.607])$. Moreover, simple slope analyses showed that in the autotelic condition, maximizing was positively associated with choice satisfaction $(B=0.18, S E=0.09, p=.045)$, whereas in the instrumental condition, maximizing was negatively associated with choice satisfaction, although not significantly so $(B=-0.15, S E=0.10, p=.13)$. The interaction remained significant after controlling for participants' cheese expertise $(B=-0.34, S E=0.13, p=.013$, $95 \% \mathrm{CI}=[-0.604,-0.072])$. Descriptive statistics and inter-correlations of all measures are provided in Table 2. In short, results showed that maximizers experienced higher choice satisfaction when making a choice for the sake of choosing (autotelic goal) rather than for an external purpose such as learning (instrumental goal).

Table 2 Descriptive statistics and inter-correlations of variables in study 2

\begin{tabular}{lllll}
\hline & 1 & 2 & 3 & 4 \\
\hline 1. Maximizing & - & - & - & - \\
2. Choice satisfaction & 0.03 & - & - & - \\
3. Perceived ease & -0.09 & $0.40^{* *}$ & - & - \\
4. Willingness to pay & 0.10 & $0.18^{*}$ & 0.10 & - \\
Mean & 4.68 & 6.16 & 4.99 & 6.48 \\
Standard deviation & 1.05 & 0.97 & 1.77 & 4.38 \\
Min. & 2.00 & 1.00 & 1.00 & 0.00 \\
Max. & 7.00 & 7.00 & 7.00 & 12.00 \\
Cronbach's alpha & 0.88 & - & - & - \\
\hline
\end{tabular}

$* p<.05 ; * * p<.01$ 


\subsubsection{Mediation through perceived ease}

To examine whether maximizers (as opposed to satisficers) find choice easier when the goal is autotelic rather than instrumental, a moderation model with 5000 bootstraps was tested (PROCESS model 1; Hayes 2013) with perceived ease as the dependent variable. Results revealed a significant interaction between choice goal and maximizing $(B=-0.73, S E=0.24, p=.003,95 \% \mathrm{CI}=[-1.207,-0.258])$. Spotlight analyses showed that maximizers found choice easier in the autotelic $(M=5.41)$ than in the instrumental condition $(M=4.12)(B=-1.29, S E=0.36$, $p<.001,95 \% \mathrm{CI}=[-1.993,-0.580])$, whereas for satisficers, there were no differences between autotelic $(M=5.03)$ and instrumental choices $(M=5.29)$ $(B=0.26, S E=0.36, p=.47,95 \% \mathrm{CI}=[-0.448,0.962])$. Simple slope analyses further showed that in the autotelic condition, maximizing was positively but not significantly associated with perceived ease $(B=0.18, S E=0.17, p=.29)$, whereas in the instrumental condition, maximizing was negatively associated with perceived ease $(B=-0.55, S E=0.17, p=.002)$. The interaction remained significant after controlling for expertise $(B=-0.54, S E=0.26, p=.037,95 \% \mathrm{CI}=[-1.052$, - 0.029]). Additionally, a moderated mediation model with 5000 bootstraps (PROCESS model 8; Hayes 2013) tested whether perceived ease explains why maximizers are more satisfied with autotelic versus instrumental choice goals (hypothesis 3). Results showed that the index of moderated mediation was significant $(-0.15, S E($ Boot $)=0.07,95 \%$ CI $=[-0.319,-0.047])$ (Fig. 2). Specifically, the conditional indirect effect of choice goal on choice satisfaction through perceived ease was significant for maximizers $(B=-0.27, S E=0.11,95 \% \mathrm{CI}=[-0.544,-0.099])$, but not for satisficers $(B=0.05, S E=0.08,95 \% \mathrm{CI}=[-0.091,0.234])$. The moderated mediation model remained significant after controlling for expertise $(-0.16, S E($ Boot $)=0.07,95 \% \mathrm{CI}=[-0.314,-0.047])$. These analyses indicate that an autotelic versus an instrumental frame makes maximizers (as opposed to satisficers) more satisfied with their choice due to making them feel as though the choice is easier.

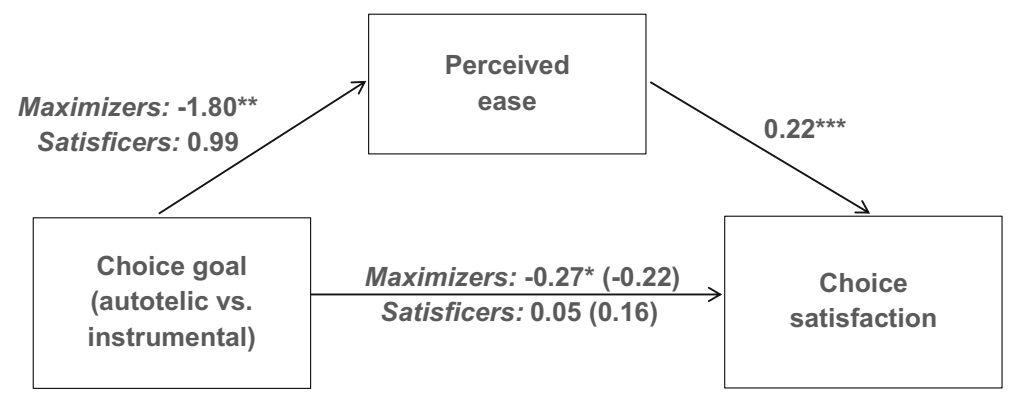

Fig. 2 Indirect effect of choice goal $(0=$ autotelic; $1=$ instrumental $)$ on choice satisfaction through perceived ease for maximizers and satisficers (in parenthesis, the direct effect controlling for perceived ease). Unstandardized regression coefficients are provided along the paths. *No zero between LLCI and ULCI. ** $p<.01$; $* * * p<.001$ 


\subsubsection{Downstream consequences on WTP}

Finally, to examine whether maximizers' higher satisfaction with autotelic versus instrumental choice goals also has downstream consequences on their WTP for their chosen option (hypothesis 4), a moderated mediation model with 5000 bootstraps was tested (PROCESS model 8; Hayes 2013). Results showed that the index of moderated mediation was significant $(-0.24, S E$ (Boot) $=0.15,95 \% \mathrm{CI}=[-0.660,-0.023])$. Specifically, the conditional indirect effect of goal condition on WTP through choice satisfaction was significant for maximizers $(B=-0.37, S E=0.24,95 \% \mathrm{CI}=[-0.110$, - 0.029]), but not for satisficers $(B=0.14, S E=0.17,95 \% \mathrm{CI}=[-0.087,0.644])$. However, a moderation analysis (PROCESS model 1; Hayes 2013) with WTP as the dependent variable yielded no significant interaction $(-0.69, S E=0.26, p=.26,95 \%$ $\mathrm{CI}=[-1.900,-0.518])$, indicating that the interaction effect of choice goal and maximizing on WTP was only significant through choice satisfaction. In other words, maximizers' higher satisfaction with autotelic versus instrumental choices increased the price that maximizers were willing to pay for their choices.

\section{Discussion}

This research examined maximizers' and satisficers' satisfaction with their choices by introducing the distinction between autotelic choice, which is a goal in itself, and instrumental choice, which is a means to achieving other goals. Study 1 (correlational) showed that maximizers value autotelic goals more than satisficers. Study 2 (experimental) showed that if the choice goal is framed as autotelic (versus instrumental), choice satisfaction is higher for maximizers than for satisficers. The underlying mechanism of this effect is a differentiated perception of the ease of the choice. As the autotelic (versus instrumental) choice better fits maximizers' disposition to always choose the best than satisficers' tendency to settle for merely "good enough," maximizers perceive such a choice as easier and this subjective perception of ease drives their satisfaction. Moreover, higher choice satisfaction in turn translates to higher WTP for their chosen option.

\subsection{Theoretical and practical contributions}

These findings provide novel insights into consumer decision-making and make a number of theoretical and managerial contributions. First, they contribute to the growing literature examining moderators of maximizers' satisfaction with their choices, such as reversible versus irreversible choices (Shiner 2015) or maximization goals versus strategy (Hughes and Scholer 2017). Second, they converge with recent studies showing that maximizers' choice satisfaction is undermined by a high responsiveness to normative concerns, such as choosing the objectively best option (Luan and Li 2017a), and external influences, such as comparing one's choices with others' choices (Weaver et al. 2015). The current research suggests one way to remedy this. Shifting maximizers' focus from extrinsic standards to the intrinsic meaning of choosing may calibrate their inner compass and increase their choice satisfaction. Third, these results add to the literature questioning the assumption that maximizers are less satisfied than 
satisficers (e.g., Diab et al. 2008; Kokkoris 2016) and draw attention to the interaction between maximizing and features of the choice task, such as consumer goals. Fourth, this research elaborates on the link between maximizing and search for meaning by focusing on stimulus-dependent satisfaction rather than broader assessments of subjective well-being (Kokkoris 2016). Fifth, another novel insight of these findings is that satisficers may not benefit from autotelic (versus instrumental) choices as much as maximizers do. If anything, they even tend to be more satisfied with instrumental choices, although not significantly so. This resonates with recent research showing that satisficers, compared to maximizers, are more concerned about practical issues such as feasibility (Luan and Li 2017b). This finding also points to a potential boundary condition of self-determination theory, which is in line with recent research exploring such conditions (e.g., Abeyta et al. 2017; Chen and Sengupta 2014). Finally, the current findings also have important managerial implications. They suggest that marketing communication strategies that activate autotelic goals may be particularly effective in pleasing consumers who are maximizers and are thought of as being hard to satisfy.

\subsection{Limitations and future research}

As a foray into a new topic, there are a few limitations of this research. Whereas study 1 provided evidence about the link between maximizing and autotelic goals at the personality level, thus implicating a variety of situations pertaining to autotelic goals, study 2 experimentally tested the hypothesis in only one consumer domain. Future research can test whether this effect generalizes across domains. However, by using a rather inconsequential choice task and a product domain that is low in symbolism, this research can be considered a rather conservative test of the hypothesis. Moreover, only one type of instrumental goal was studied, namely, a learning focus. Future research could examine the impact of other types of instrumental goals as well, such as self-presentation goals. Additionally, these findings invite further research on other features of the choice task that can affect choice satisfaction differently among maximizers and satisficers. Finally, autotelic and instrumental goals in this research were conceptualized as a dichotomy based on ideal types. However, they may also be conceptualized as two ends of a continuum. Future research can examine more fine-grained distinctions between goals, as well as the possibility that there might be discrepancies between explicit and implicit goals (e.g., what is perceived as an autotelic goal at an explicit level might be instrumental at an implicit level).

\subsection{Conclusion}

In a nutshell, this research advances understanding of consumer decision-making by exploring the role of consumer goals in determining maximizers' and satisficers' choice satisfaction. According to preliminary evidence presented here, maximizers might be better understood as consumers actively seeking self-contained meaning in choice. As such, they may benefit more from searching for meaning and purpose inherent in choice rather than in external goals. After all, it is the journey that matters and not the destination and this might be particularly true for those who truly aspire to make the best of the journey.

Acknowledgements Open access funding provided by Vienna University of Economics and Business (WU). The author would like to thank the editor and two anonymous reviewers for their valuable comments. 
Open Access This article is distributed under the terms of the Creative Commons Attribution 4.0 International License (http://creativecommons.org/licenses/by/4.0/), which permits unrestricted use, distribution, and reproduction in any medium, provided you give appropriate credit to the original author(s) and the source, provide a link to the Creative Commons license, and indicate if changes were made.

\section{References}

Aaker, J. L., \& Lee, A. Y. (2006). Understanding regulatory fit. Journal of Marketing Research, 43, 15-19.

Abeyta, A. A., Routledge, C., \& Sedikides, C. (2017). Material meaning: narcissists gain existential benefits from extrinsic goals. Social Psychological Personality Science, 8, 219-228.

Asakawa, K. (2004). Flow experience and autotelic personality in Japanese college students: how do they experience challenges in daily life? Journal of Happiness Studies, 5, 123-154.

Baumann, N. (2012). Autotelic personality. In S. Engeser (Ed.), Advances in flow research (pp. 165-186). New York: Springer.

Baumeister, R. F., Vohs, K. D., Aaker, J. L., \& Garbinsky, E. N. (2013). Some key differences between a happy life and a meaningful life. The Journal of Positive Psychology, 8, 505-516.

Besharat, A., Ladik, D. M., \& Carrillat, F. A. (2014). Are maximizers blind to the future? When today's best does not make for a better tomorrow. Marketing Letters, 25, 77-91.

Botti, S., \& McGill, A. L. (2011). The locus of choice: personal causality and satisfaction with hedonic and utilitarian decisions. Journal of Consumer Research, 37, 1065-1078.

Buhrmester, M., Kwang, T., \& Gosling, S. D. (2011). Amazon's Mechanical Turk: a new source of inexpensive yet high-quality data? Perspectives on Psychological Science, 6, 3-5.

Busch, H., Hofer, J., Chasiotis, A., \& Campos, D. (2013). The achievement flow motive as an element of the autotelic personality: predicting educational attainment in three cultures. European Journal of Psychology of Education, 28, 239-254.

Carrillat, F. A., Ladik, D. M., \& Legoux, R. (2011). When the decision ball keeps rolling: an investigation of the Sisyphus effect among maximizing consumers. Marketing Letters, 22, 283-296.

Casler, K., Bickel, L., \& Hackett, E. (2013). Separate but equal? A comparison of participants and data gathered via Amazon's MTurk social media and face-to-face behavioral testing. Computers in Human Behavior, 29, 2156-2160.

Cheek, N. N., \& Schwartz, B. (2016). On the meaning and measurement of maximization. Judgment and Decision making, 11, 126-146.

Chen, F., \& Sengupta, J. (2014). Forced to be bad: the positive impact of low-autonomy vice consumption on consumer vitality. Journal of Consumer Research, 41, 1089-1107.

Choi, J., \& Fishbach, A. (2011). Choice as an end versus a means. Journal of Marketing Research, 48, 544 554.

Chowdhury, T. G., Ratneshwar, S., \& Mohanty, P. (2009). The time-harried shopper: exploring the differences between maximizers and satisficers. Marketing Letters, 20, 155-167.

Csikszentmihalyi, M. (1990). Flow: the psychology of optimal experience. New York: Harper \& Row.

Csikszentmihalyi, M. (1997). Finding flow: the psychology of engagement with everyday life. New York: Basic Books.

Csikszentmihalyi, M., Rathunde, K., \& Whalen, S. (1993). Talented teenagers: the roots of success \& failure. New York: Cambridge University Press.

Dalal, D. K., Diab, D. L., Zhu, X. S., \& Hwang, T. (2015). Understanding the construct of maximizing tendency: a theoretical and empirical evaluation. Journal of Behavioral Decision Making, 28, 437-450.

Diab, D. L., Gillespie, M. A., \& Highhouse, S. (2008). Are maximizers really unhappy? The measurement of maximizing tendency. Judgment and Decision making, 3, 364-370.

Hauser, D. J., \& Schwarz, N. (2016). Attentive Turkers: MTurk participants perform better on online attention checks than do subject pool participants. Behavior Research Methods, 48, 400-407.

Hayes, A. F. (2013). Introduction to mediation, moderation, and conditional process analysis: a regressionbased approach. New York: Guilford Press.

Higgins, E. T. (2005). Value from regulatory fit. Current Directions in Psychological Science, 14, $209-213$.

Homburg, C., Koschate, N., \& Hoyer, W. D. (2005). Do satisfied customers really pay more? A study of the relationship between customer satisfaction and willingness to pay. Journal of Marketing, 69, 84-96.

Hughes, J., \& Scholer, A. A. (2017). When wanting the best goes right or wrong: distinguishing between adaptive and maladaptive maximization. Personality and Social Psychology Bulletin, 43, 570-583. 
Iyengar, S. S., Wells, R. E., \& Schwartz, B. (2006). Doing better but feeling worse: Looking for the "best" job undermines satisfaction. Psychological Science, 17, 143-150.

Johnson, J. A., Keiser, H. N., Skarin, E. M., \& Ross, S. R. (2014). The dispositional flow scale-2 as a measure of autotelic personality: an examination of criterion-related validity. Journal of Personality Assessment, 96, 465-470.

Kasser, T., \& Ryan, R. M. (1996). Further examining the American dream: differential correlates of intrinsic and extrinsic goals. Personality and Social Psychology Bulletin, 22, 280-287.

Kokkoris, M. D. (2016). Revisiting the relationship between maximizing and well-being: an investigation of eudaimonic well-being. Personality and Individual Differences, 99, 174-178.

Lai, L. (2010). Maximizing without difficulty: a modified maximizing scale and its correlates. Judgment and Decision making, 5, 164-175.

Laran, J., \& Janiszewski, C. (2011). Work or fun? How task construal and completion influence regulatory behavior. Journal of Consumer Research, 37, 967-983.

Leach, J. K., \& Patall, E. A. (2013). Maximizing and counterfactual thinking in academic major decision making. Journal of Career Assessment, 21, 414-429.

Luan, M., \& Li, H. (2017a). Maximization paradox: result of believing in an objective best. Personality and Social Psychology Bulletin, 43, 652-661.

Luan, M., \& Li, H. (2017b). Good enough — compromise between desirability and feasibility: an alternative perspective on satisficing. Journal of Experimental Social Psychology, 70, 110-116.

McNeill, I. M., Higgins, E. T., De Dreu, C. K., \& Nijstad, B. A. (2012). The price of a piece of cheese: value from fit between epistemic needs and a learning versus an outcome focus. Journal of Behavioral Decision Making, 25, 315-327.

Misuraca, R., \& Teuscher, U. (2013). Time flies when you maximize - maximizers and satisficers perceive time differently when making decisions. Acta Psychologica, 143, 176-180.

Nakamura, J., \& Csikszentmihalyi, M. (2002). The concept of flow. In C. R. Snyder \& S. J. Lopez (Eds.), Handbook of positive psychology (pp. 89-105). New York: Oxford University Press.

Oishi, S., Tsutsui, Y., Eggleston, C., \& Galinha, I. C. (2014). Are maximizers unhappier than satisficers? A comparison between Japan and the USA. Journal of Research in Personality, 49, 14-20.

Oppenheimer, D. M., Meyvis, T., \& Davidenko, N. (2009). Instructional manipulation checks: detecting satisficing to increase statistical power. Journal of Experimental Social Psychology, 45, 867-872.

Paolacci, G., Chandler, J., \& Ipeirotis, P. (2010). Running experiments on Amazon Mechanical Turk. Judgment and Decision making, 5, 411-419.

Peck, J., \& Childers, T. L. (2003). Individual differences in haptic information processing: the "need for touch" scale. Journal of Consumer Research, 30, 430-442.

Peer, E., Brandimarte, L., Samat, S., \& Acquisti, A. (2017). Beyond the Turk: alternative platforms for crowdsourcing behavioral research. Journal of Experimental Social Psychology, 70, 153-163.

Polman, E. (2010). Why are maximizers less happy than satisficers? Because they maximize positive and negative outcomes. Journal of Behavioral Decision Making, 23, 179-190.

Rim, H. B., Turner, B. M., Betz, N. E., \& Nygren, T. E. (2011). Studies of the dimensionality, correlates, and meaning of measures of the maximizing tendency. Judgment and Decision making, 6, 565-579.

Ross, S. R., \& Keiser, H. N. (2014). Autotelic personality through a five-factor lens: individual differences in flow-propensity. Personality and Individual Differences, 59, 3-8.

Ryan, R. M. (1982). Control and information in the intrapersonal sphere: an extension of cognitive evaluation theory. Journal of Personality and Social Psychology, 43, 450-461.

Ryan, R. M., \& Deci, E. L. (2000). Self-determination theory and the facilitation of intrinsic motivation, social development, and well-being. The American Psychologist, 55, 68-78.

Schwartz, B., Ward, A., Monterosso, J., Lyubomirsky, S., White, K., \& Lehman, D. R. (2002). Maximizing versus satisficing: happiness is a matter of choice. Journal of Personality and Social Psychology, 83, 1178-1197.

Shiner, R. L. (2015). Maximizers, satisficers, and their satisfaction with and preferences for reversible versus irreversible decisions. Social Psychological and Personality Science, 6, 896-903.

Weaver, K., Daniloski, K., Schwarz, N., \& Cottone, K. (2015). The role of social comparison for maximizers and satisficers: wanting the best or wanting to be the best? Journal of Consumer Psychology, 25, 372388.

Weinhardt, J. M., Morse, B. J., Chimeli, J., \& Fisher, J. (2012). An item response theory and factor analytic examination of two prominent maximizing tendency scales. Judgment and Decision making, 7, 644-658.

Zhu, X. S., Dalal, D. K., \& Hwang, T. (2017). Is maximizing a bad thing? Linking maximizing tendency to positive outcomes through future-oriented thinking. Journal of Individual Differences, 38, 94-101. 